\title{
The Examination of 5-6 Year-Old Children's Ability to Use Simple Maps
}

\author{
Esin Dibek ${ }^{1}$, Atiye Adak Özdemir ${ }^{1}$, Yıldız Güven $^{1}$ \\ ${ }^{1}$ Marmara University, Turkey \\ Correspondence: Esin Dibek, Marmara University, Turkey. \\ Received: December 25, 2018 \\ Accepted: February 11, 2019 Online Published: February 26, 2019 \\ doi:10.11114/jets.v7i3.3904 \\ URL: https://doi.org/10.11114/jets.v7i3.3904
}

\begin{abstract}
The main purpose of this study was to assess children's skill in using a simple map. The study was conducted among 262 children (141 girls and 121 boys), aged between 61-78 months (average 71 months), attending to 4 public pre-schools in Istanbul, Turkey. The simple map skills (requiring mental rotation and understanding spatial relation) of the participants were tested through five different experimental trials. Children's skills in using simple maps were analyzed by age, gender, and children's performances in different experimental conditions.

The data were analyzed using logistic regression analysis. It was found that children's performance in the experiments did not vary by gender. Likewise, their performance did not vary by age. However, there were significant differences in children's performances in the five different experimental conditions. According to findings, children were more successful in trial 1 which is requiring the understanding of spatial relations compared to the trial 2 and 3 which are requiring mental rotation. Finally results are discussed in terms of variables which may lead to the researchers and educators working on spatial abilities of children.
\end{abstract}

Keywords: preschool, children, map skills, mental rotation, spatial relation

\section{Introduction}

Spatial thinking is an important component of cognition (Borriello and Liben, 2018) and has a central role in the process of a human's being adaptation to his environment (Güven,2004; Newcombe and Huttenlocher, 2000). Spatial-thinking is functional in the brain from an early age (Gersmehl and Gersmehl, 2007). Researchers are in consensus about the role of an individual's spatial ability in being successful in later life in many areas such as science and mathematics (Erkek and Bostan-Işıksal, 2015; Gilligan et al., 2017 Ferguson, Maloney, Fugelsang and Risko, 2015; Hawes, LeFevre, Xu and Bruce, 2015; Ping et al., 2011; Zhang et al., 2014; Turgut and Y1lmaz, 2012; Verdine, Golinkoff, Hirsh-Pasek, Newcombe, Flipovicz, and Chang, 2014). Gunderson, Ramirez, Beilock and Levine (2012) stated that a very young child's spatial performance predict his or her future success in creating and using linear number-line representations in mathematics. According to Clements (1998), spatial skills, that include mental sliding, turning, and rotating of objects, play an important role in interpreting, describing and deeply thinking about our surrounding objects (as cited in Sar1, 2016). Newcombe et al. (2013) categorized spatial cognition into two main areas; navigation and mental rotation.

Spatial skills are very important in assisting children navigate across areas and to use objects in different ways within the course of their daily lives (through mental rotation) (Baykal, Alaca, Yantaç and Göksun, 2018; Ferrara, Hirsh-Pasek, Newcombe, Golinkoff and Lam, 2011). Navigation is a complex process (Wolbers and Hegarty, 2010). This is seen from birth as children, through their curiosity and perceptions, begin to explore their environment and learn the location, distance, time and concepts that represent them, which are related to space (Melendez, Beck and Fletcher, 2000). Spatial perception helps them understand the relationships between entities, facilitates the perception of geographic concepts, the disclosure of relationships between them, and explains their cause and effects (Bahar, Sayar and Başıüyük, 2010). On the other hand, mental rotation refers to rotating two and three-dimensional objects in the mind. In other words, it is the mental conversion of locational-directional changes in a spatial representation.

Information about the surrounding and the world, can be acquired through direct experiences such as travelling and residing in an environment, or through secondary sources within the context of spatial representations, such as maps, written sources (e.g books, etc.), models, or visual sources (e.g. film, television, etc.) (Blades, Spencer, Plester and Desmond, 2004; Plester, Blades and Spencer, 2006). Secondary sources used to obtain information about the 
surrounding are portable representations which therefore make visible information about immense and hard-to-reach spaces.

Maps are tools that provide information about space (Kızılçaoğlu, 2007). Maps help children understand spatial relations (Blades, 2000). In the real world, individuals use maps to guide their journeys. Maps are the representation of a three-dimensional world on a two-dimensional surface (Ginsburg and Amit, 2008). Using a mapreqiures basic spatial skills employed in daily life (Bremner and Andreasen, 1998). To be able to use a map, an individual ought to be aware of symbolic representations of actual objects on the map (Liben, 1999; cited as in Vosmik, 2005; Robinson and Petchenik, 1976). Children should be able to relate the actual spatial context to the information on the map that represents it (Vasilyeva and Bowers, 2010). Accordingly, using a map is associated with encoding two types of information. Firstly, is object-object similarity, and secondly, similarity in spatial relationships. Object-object similarity is the ability of children to understand that each object in the map or model has a counterpart in the area represented by the map (Newcombe and Huttenlocher, 2000). In addition, they should also recognize that these tools (like maps) are small-scale representation of larger spaces (Newcombe and Learmonth, 2005). Map understanding comprises three components: the first one is symbolic representations, the second is use of spatial relations and the third is mental rotation (Peter, Glück and Beiglböck, 2010). The first studies related to children's map skills can be traced to Piaget and Inhelder. These studies conducted within the scope of spatial development, concluded that children don't possess the skills that form the basis for map reading (such as mental rotation and perspective taking), before the ages of 7-10 years (By: Newcombe Frick, 2010). A review of the literature illustrates research outcomes (Harvey, Manshu, and Jue, 1986) that support Piaget's views about spatial development in children. However, recent studies show that these skills may emerge at an earlier period (Ages 3-6) (Blaut, Stea, Spencer and Blades, 2003; Michaelidou, Filippakopoulou and Nakos, 2007; Kim, Bednarz \& Kim, 2012; Tsubota and Chen, 2012).

Recent studies have shown that children recognize relationships between the maps and real world as early as the age of three (Shusterman, Lee, Spelke, 2008), and start to use spatial relations in simple maps from the age of four (Vasilyeva and Bowers, 2010). Other researchers have defined ideas and actions that constitute reading, using and creating maps and similar models (mapping behavior), as a skill that exists in early childhood in all cultures independent of the formal education, as a function of human adaptation to the environment(Blaut, Stea, Spencer and Blades, 2003). Children use simple maps for the purpose of finding the location of an object hidden in an open area (Stea, Kerkma, Pinon, Middlebrook and Rice, 2004; Tsubota and Chen, 2012); determining the direction of objects in a large closed area (Sadberg and Huttenlocher, 2001); and finding an object hidden in a labyrinth (Bremner and Andreasen, 1998). In order to find a spot marked on a map, an individual should match the element it represents on an actual field with the one on the map. A research study showed that children aged $31 \frac{1}{2}$ years possessed this skill if the map and hidden location were aligned (by Blades and Spencer, 1994).

The sketch and map, which in their abstract forms are visual tools, can be considered as a technique that summarizes information. In sketches, drawings are more generic and in draft form, whereas in maps drawings are accurate and scaled. Children should be able to properly read sketches and maps in order to be able to use them. Reading and drawing sketches which facilitate daily living are important skills for space detection (Bahar, Sayar and Başıbüyük, 2010).

Researchers suggest that the majority of 3-4-year-olds are ready to learn simple information about maps. At these ages, children can interpret a living-room plan and can find the location of a toy hidden in the room by looking at a spot on the plan (Shusterman et al., 2008; Vasilyeva and Huttenlocher, 2004). Stea, Kerkma, Pinon, Middlebrook and Rice (2004) showed that 3-5 year-olds and 5-year-old pre-school children could successfully use a simple map to find the location of an object hidden in an open area. Determining the extent to which children can use spatial representation tools such as simple maps (i.e. their spatial skills), is believed to be important in guiding educational planning as regards the acquisition of this skill in the early childhood period. In this study, it was developmentally more appropriate to commence the examination of children's map skills using plans-sketches.

The main purpose of this study was to assess children's skill in using simple maps and to understand the relationship between simple maps and the represented space (model). The main research questions were as follows:

1. Does the performance of the children vary by different experimental conditions?

2. Does the performance of the children vary by age and gender?

In this study, children's skill in using simple maps was analyzed by age, gender, the alignment or rotation of the map and model, who placed the object on the model (i.e. the child or other) and whether a particular spot was taken as a reference spot. 


\section{Research Methodology}

\subsection{Study Participants}

The study was conducted among 262 children (141 girls and 121 boys), aged between 61 and 78 months (mean age 71 months), attending to 4 public pre-schools in Istanbul, Turkey.

\subsubsection{Participant Selection}

The 262 children were selected from 280 children at 4 public pre-schools. Two criteria were used the selection of the children. One of them is the children are being older than 60 months. The second one of them is the children are able to understand five basic spatial concepts (on, in, under, in front of, and behind) correctly. All children who meet these conditions in these schools were involved to the study.

\subsection{Practitioners}

The study was conducted by seven $4^{\text {th }}$-grade-students from Marmara University, Atatürk Education Faculty, Pre-School Education Division of Primary Education Department, within the scope of a Research Project course.

2 practitioners worked together on each trial, one of them made observations and took notes (P1) while the other executed the trials with each child (P2). Practitioners were trained during pilot trials performed under the surveillance of experienced researchers.

\subsection{Materials Used}

The materials used were: 14 square boxes $(5 \times 5 \times 5 \mathrm{~cm})$, a cardboard ground-surface on which the boxes were placed $(35 \times 50 \mathrm{~cm})$ (Figure 1), small size plastic figures - dog and cat (Figure 2), and a simple map of A4 size, showing the layout of the boxes (Figure 2). The dog figure is not the main character of the study. However it is located on the table next to the cardboard and pointed at by the practitioner when mentioned. The materials used in the execution of the project and the 5 experimental trial employed were established through research studies carried out under the guidance of experienced researchers.

The material used in five experimental trials was shown in Figure 1.

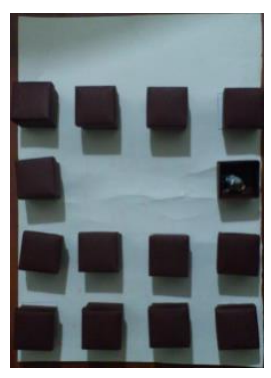

Figure 1. The material used in five experimental trials

\subsection{Experimental Trials}

\subsubsection{Description of Experimental Trials}

According to the study's sub-goals, 5 different levels of experiment were designed. Two of them asses the child's mental rotation (trials 2 and 3) and the others (trials 1, 4,5) assess the child's understanding of spatial relation. These were:

\section{Matching locations on the map to locations on the model when map and model were in alignment}

Trial 1: These tasks assess the child's understanding of spatial relation. In this trial, the child was asked to find the location of a figure hidden in one of the boxes in the model (Figure 1) by looking at the location of the box marked on the simple map (See Figure 1-Figure 2).

Matching locations on the map to locations on the model when map was rotated 180 degrees relative to the model without a reference point

Trial 2: In the most difficult task, the map is not aligned with the model, so mental rotation is required. In this trial, the child was asked to find the location of a figure hidden in one of the boxes in the model (Figure 1) by looking at location of the box marked on the simple map after the map was rotated by 180 degrees (rotation) in relation to the model (See Figure 3).

Matching locations on the map to locations on the model when map was rotated 180 degrees relative to the model with a reference point 
Trial 3: This trial was similar to T2. However, a box next to the target box was removed from both the model and from the map. The child was then asked to find the correct location of the figure hidden in the box by looking at the location of the box marked on the simple map (See Figure 4).

Matching locations on the model to locations on the map when object and map were in alignment and object was placed on the model by the practitioner

Trial 4: These tasks assess the child's understanding of spatial relation. In this trial the child was asked to match the location of a figure, which was placed in one of the boxes by the practitioner in full view of the child, to the location of the box on the simple map (See Figure 5).

Matching locations on the model to locations on the map when object and map were in alignment and object was placed on the model by the child

Trial 5: These tasks assess the child's understanding of spatial relation. In this trial the child was asked to place a figure in one of the boxes on the model and identify the corresponding location of the figure in the box to a location on the simple map.

Note: Excluding trial 5, all locations of the target boxes and/or their corresponding marked boxes on the simple map were pre-defined and were presented to all children in a similar fashion, i.e., all the children were subjected to the same assessment test.

\subsubsection{Preparation of Materials Prior to Execution}

Practitioners placed the boxes on the card board ground as per preplanned specifications to ensure that that each box was equidistant from the other distance (the distance between the boxes being equal to the length of each box) prior to allowing each child into the practice environment.

\subsubsection{Meeting with the Children}

Practitioners then went to the children's classes, introduced themselves and invited them to play with them as follows, "Today we will play a game with you, who wants to play with us?" Children who volunteered to participate were invited to the practice environment. In an instance when all children were willing to participate, practitioners thanked them by saying, "It is very nice to see all of you want to join, you will play all one after another." One by one, the children were taken to the practice environment in the order of their class list.

\subsubsection{Preliminary Evaluation}

Prior to the child's arrival at the practice environment, the first practitioner (P1) wrote down the name and other information pertaining to the child. When the child arrived, P1 begun to observe the child's behavior that pertained to the activity.

The second practitioner (P2) then invited the child to sit at the table by saying, "Welcome ..... (child's name). Now, we will play a game with you." P2 would then seat across the same table opposite the child.

The prerequisite for participation in experiment was an ability to give correct answers to all basic spatial concepts, such as front, rear, top, inside and next. For this purpose, P2 put one of the boxes used in the trial and the cat figure on the table. P2 then went on to evaluate whether the child was able to perform the instructions associated with spatial concepts by giving instructions such as, "Put the cat behind the box", "Put the cat inside the box", etc.

The execution of the experimental trials ensued with 262 of 280 children, who correctly followed instructions associated with these five main concepts (on, in, under, in front of, and behind). The other 18 children who had been willing to participate in the trials, but did not pass the preliminary evaluation, were still allowed to play with the boxes and the cats for a while to limit chances of disappointment.

\subsubsection{Execution}

P2 put the cat inside a box on the model and closed the cover of the box before the child entered the room. The boxes were placed on the table in alignment with the simple map (See Figure 1). The model and the simple map were then placed in front of the child.

P2 then allowed the child to look at the boxes and the simple map and said, "Look, there are many boxes here. Watch how the boxes are placed, now look at this simple map (pointing the plan), the boxes here are placed according to the simple map". P2 then asked the child, "Did you look at it carefully?". P2 would then start the trial upon getting an affirmative response from the child such as nodding or statements like "yes". 

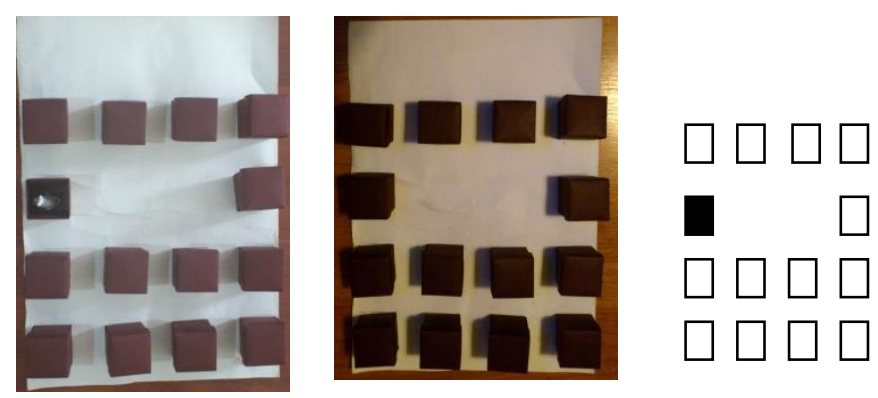

Figure 2. Representation of Trial 1

P2 would show the child the Puffy (a cat) figure and tell a story as follows: "Pepper (dog) and his friend Puffy were playing hide and seek. Puffy was hidden in one of these boxes (P2 would then points at the model in Figure 2). "The box, in which Puffy was hidden, is marked on this simple map" (P2 would then point to the spot colored black on Figure 2). P2 would then say, “.... (name of the child) help Pepper to find the location of Puffy by looking at the simple map".

P2 then waited until the child pointed to a box. At this stage, no assistance would have been provided to the child through expressions that indicated approval (e.g nodding, guiding with hands, pointing, etc.), unless the child stayed impartial or responded by saying, "I cannot find", or "I cannot make."P2 would then encourage the child by saying, "I believe that you will find Puffy", "I believe that you will achieve".
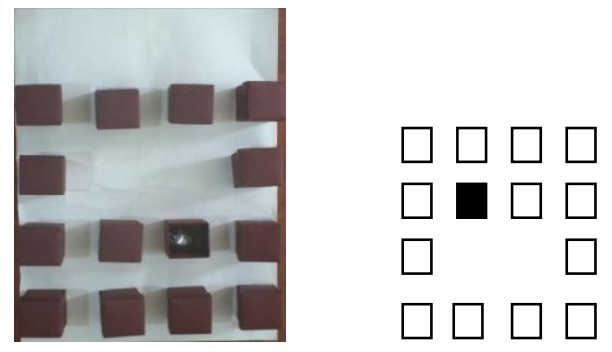

Figure 3. Representation of Trial 2

The execution process for this trial was similar to T1. However, prior to commencing the trial, P2 took the child to a place where he/she could not see the boxes. P1 then placed the cat figure inside the pre- determined box for this trial (Figure 3) and closed the lid of the box. P2 and the child then returned to the table with the model, the simple map which had been rotated by 180 degrees (Figure 3), was given to the child. P2 then instructed the child to look at the simple map and the model carefully. P2 then repeated the story in T1 to the child and waited for the child to identify the box marked on 180-degree-rotated simple map on the model.
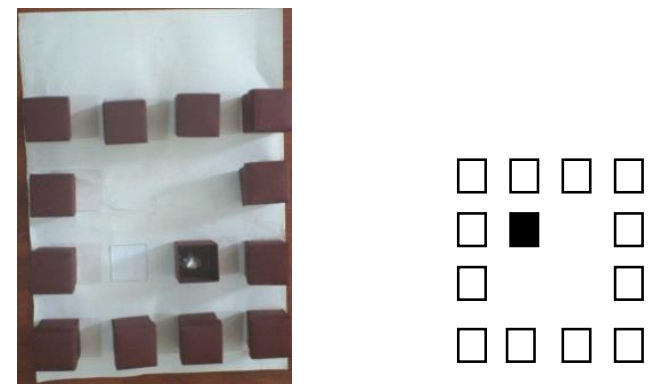

Resim 8

Figure 4. Representation of Trial 3

The execution process of this trial was similar to T2. However, in T3, a reference point was created by removing a box (next to the target box where the figure was hidden) from both the model and the simple map (Figure 4). This was done 
with the expectation that a child will find it easier to identify the target box using his or her rotation skills. P2 then waited for the child to find the box marked on 180-degree-rotated simple map and identify it on the model.

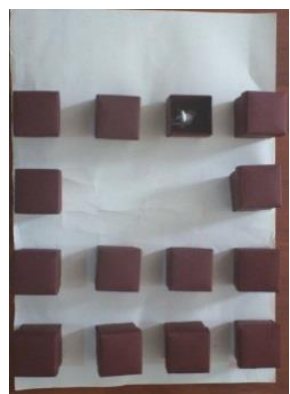

Resim 10

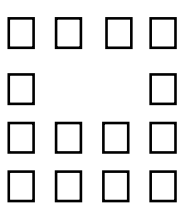

Resim 11

Figure 5. Representation of Trial 4

P2 placed the model and the simple map in alignment (Figure 5) in front of the child. At this stage, the covers of all boxes would be opened. P2 then put the cat inside a pre- determined box, gave the child a pencil and showed the cat figure to the child and said, "Please mark the location of Puffy on this simple map for Pepper to find him". In this marking stage, the child was asked to put a mark on the simple simple map where he/she thought would correspond to the location of the cat on the model.

Trial 5 (A5): (Figure 5) P2 placed the model and the simple map in alignment (Figure 5) in front of the again. At this stage, the covers of all boxes would still be open. P2 then pointed to the cat figure and said, "Now, hide Puffy in a place that you want." After this P2 would say, "Please mark the location of Puffy on this plan for Pepper to find him". P2 would then wait for the child to mark the location of the cat on the simple map.

When the trials were completed, P2 informed the child that the game was over, thanked him or her for participating and took him/her back to the classroom.

\subsubsection{Scoring}

In all stages, the scoring was made by giving 1 point for a correct answer and 0 (zero) points for a wrong answer.

\subsection{Data Analysis}

The outcomes of these experimental trials were recorded as either successful or unsuccessful. The data were analyzed using logistic regression analysis for repeated binary measures i.e. Generalized Estimating Equations using PASW version 18.0. Generalized Estimating Equations are an extension of Generalized Linear Models to a regression setting with repeated correlated observations from each subject (Liang and Zeger, 1986; Horton and Lipsitz, 1999).

\section{Results}

The main purpose of this study was to assess children's skill in using a simple map and to understand the relation of this simple map to a related space. Concerning the first research question, the findings of the study show that there were statistically significant differences in children's performances in different experimental conditions (Wald $\chi^{2}=245.31$, $\mathrm{df}=4, \mathrm{p}<0.001$ ). More specifically, children were less likely to be successful in trial 2 (Wald $\chi^{2}=100.86, \mathrm{df}=1, \mathrm{p}<0.001$, odds ratio $=0.13,95 \% \mathrm{CI}=0.087-0.19$ ) and trial 3 which are requiring mental rotation (Wald $\chi^{2}=22.25, \mathrm{df}=1, \mathrm{p}<0.001$, odds ratio $=0.46,95 \% \mathrm{CI}=0.33-0.63$ ) compared to the trial 1 which is requiring understanding spatial relations.

In contrast, children were more likely to be successful in trial 4 (Wald $\chi^{2}=21.01, \mathrm{df}=1, \mathrm{p}<0.001$, odds ratio $=2.12,95 \%$ $\mathrm{CI}=1.54-2.89$ ) and trial 5 (Wald $\chi^{2}=41.52, \mathrm{df}=1, \mathrm{p}<0.001$, odds ratio $=3.10,95 \% \mathrm{CI}=2.2-4.39$ ) compared to the trial 1. All of these practices are require understanding of spatial relationships. However, in the first trial, it is expected that the marked point on the two-dimensional representation (simple map) is to find the three-dimensional (box) equivalent while in the fourth and fifth trial the opposite is expected. Moreover, the differences between all pairs of trial conditions, except the difference between the trial 4 and 5 ( $\mathrm{p}=0.335)$, were also statistically significant $(\mathrm{p}<0.001)$.

Concerning the second research question, the findings of the study demonstrated that boys and girls do not differ on their performances in the any of experimental conditions (Wald $\chi 2=1.16, \mathrm{df}=1, \mathrm{p}=0.28$ ). Likewise, the age difference was not statistically significant (Wald $\chi^{2}=3.6, \mathrm{df}=2, \mathrm{p}=0.166$ ) indicating older and younger children performed similarly on all experimental trials. 


\section{Discussion and Conclusion}

This research examined pre-school children's ability to use simple maps were by employing five different trials with each child. The scores obtained from these trials revealed that map skills did not vary by gender. In the literature, no significant difference has been observed between girls and boys in terms of spatial skills (Hoyek, Collet, Fargier and Guillot, 2012; Lowenstein and Gentner, 2001; Sandberg and Huttenlocher, 2001; Spelke, Gilmore and McCarthy, 2011; Titze, Jansen and Heil, 2010; Verdine, et al., 2014). However, some studies have shown that in early childhood, boys are more skillful in spatial abilities compared to girls (Levine, Huttenlocher, Taylor and Langrock, 1999). On the other hand in Ilen's study (2016) showed significant differences in the mental folding score between boys and girls; 7-8 years old girls got better scores than boys but boys and girls were equally skilled solving mental rotation tasks.

Based on 6-month age ranges, simple map skills did not vary by children's age. The research of Stea, Kerkma, Pinon, Middlebrook and Rice (2004) revealed that 3-5 year-olds, and 5-year-old pre-school children successfully used simple maps to find the location of an object hidden in an open area. Similarly, in trials carried out by Huttenlocker, Newcombe and Vasilyeva (1999), the majority of 3-year-old and all 4-year-old children were able to use simple maps to find hidden objects. These researches indicate that children can use simple maps from early ages and their mapping skill increase with age. The absence of a significant difference may be due to the absence of, or limited exercises covering simple map skills in pre-school institutions, or alternatively, the duration of the pre-school education in Turkey country is shorter than that of developed countries.

According to the results of the current study children's success significantly varied by trial. Children were more successful in trial which are required understanding spatial relations compared to the trial which are required mental rotation. Findings of the previous study with 95 3- to 6-year-old children (Peter, Glück and Beiglböck, 2010) showed that the majority of 6-year-olds use of spatial relations whereas mental rotation of maps was shown only by two 5-years old children. Spelke, Gilmore and McCarthy (2011) asked children aged 5-6 years to use a map of a particular geometric arrangement to place an object on a location indicated on the map. Their results showed that children were able to use the map successfully in placing an object in positions where the map and the arrangement were aligned, as well as when they were rotated $\left(90^{\circ}, 180^{\circ}, 360^{\circ}\right)$. Some other researches have revealed that pre-school children are less successful on simple map reading skills when the map and the object were not in alignment (Blemner and Andreasen, 1998; Bluestein and Acredelo, 1979; Liben and Downs, 1993; Vosmik and Presson, 2004). This may be due to the insufficiency of spatial exercises in educational environments.

Children were more successful in activities that involved identifying a spot in the model on the simple plan (T4-T5) as compared to identifying a spot marked on the simple plan in the model (T1). Children were particularly more successful in marking the location of an object that they had placed themselves on the model, on the simple map (T5). This implies that children focus more on the trials when they are actively engaged in the process and consequently give correct answers.

\section{Recommendations}

In this study children's ability in using information on a simple map and the space related to it were examined. Children were able to make symbolic representations and interpret spatial relationships, but showed limited success in mental rotation skills.

Future studies analyzing children's ability to use simple maps in relation to larger, open and closed areas are recommended. They ought to examine the ability of children of different age groups' to use a map in a comparative manner. Since our research showed the existence of basic spatial skills associated with map reading (symbolic representation, spatial relationships, mental rotation) among 60-78-month-old kids, we recommend the development of various trials to build the capacity of teachers in understanding the development and significance of spatial abilities in children

The actual spatial context used in this study (model) was limited to the size that could be seen by the eyes of a child. Future researches could focus on examining the effect of same spatial context in different sizes (for example on a bigger scale) on children's success of using a simple map.

In the literature, the experiences gained using concrete objects (as blocks) before the age of 4 years are of critical importance in spatial skills development (Levine, Ratliff, Huttenlocher and Cannon, 2012). Even pointing by hand improves the mental rotation skill of 4-year-old children (Ping, Ratliff, Hickey and Levine, 2011). The living environment is full of opportunities for children to learn spatial skills and teachers in educational environments should support children in understanding 'space' in different ways. Adults are expected to ask many questions about 'space' and allow children to ask questions as well. Finally, as learning 'space' is important in cognitive development, we recommended the creation of developmentally-appropriate environmental arrangements, using concrete objects; and 
getting pre-school teachers to be proactive in providing opportunities for the development of different spatial skills (simple maps, rotation, etc.). In addition, fictional or informative books can be used by teachers to support spatial skills' development in preschool education classes (Adak- Özdemir, Güven, Özdemir-Beceren and Zembat, 2019).

Training programs may help children to develop their spatial abilities. Tzuriel and Egozi (2010) have shown that training programs focused on the teaching of representation and transformation of spatial information, brought about a significant improvement in the spatial performance of young children and significantly mitigated the initial gender gap. Adak-Özdemir and Güven (2014) showed that the Spatial Skills Education Program had positive impact on spatial skills of preschool children. Finally, further surveys are needed to confirm these results regarding the spatial abilities of children of this age-group.

\section{References}

Adak-Özdemir, A., \& Güven, Y. (2014). The effect of the spatial skills education program on the spatial skills of preschool children. International Journal on New Trends in Education and Their Implications, 5(4), 121-137. ISSN 1309-6249.

Adak-Özdemir, A., Güven, Y., Özdemir-Beceren, B., \& Zembat, R. (2019). Erken Çocuklukta Mekansal Beceriler \& Sosyal Duygusal Öğrenme Becerileri ve etkinlik örnekleri. Ankara: Vize Yayınc1lı. ISBN: 978-605-9278-67-6.

Bahar, H. H., Sayar, K., \& Başıüyük, A. (2010). İlköğretim öğrencilerinin kroki okuma becerilerinin incelenmesi (Erzincan örneği). Fırat Üniversitesi Sosyal Bilimler Dergisi, 20(1), 229-246.

Baykal, G. E., Alaca, I. V., Yantaç, E., \& Göksun, T. (2018). A review on complementary natures of tangible user interfaces and early spatial learning. International Journal of Child-Computer Interaction, 18, 104-113. https://doi.org/10.1016/j.ijcci.2018.01.003

Blades, M. (2000). Young children's understanding of indirect sources of spatial information. Commentaries. Blackwell Publishers, 265-266.

Blades, M., \& Spencer, C. (1994). The development of children's ability to use spatial representations. Advanced Child Development Behavior, 25, 157-199. https://doi.org/10.1016/S0065-2407(08)60052-X

Blades, M., Spencer, C., Plester, B., \& Desmond, K. (2004) 'Young children's recognition and representation of urban landscapes from aerial photographs and in toy play' in Allen, G. (ed) Human Spatial Memory. London: Lawrence Erlbaum, 287-308.

Blaut, J. M., Stea, D., Spencer, C., \& Blades, M. (2003). Mapping as a cultural and cognitive universal. Annals of the Association of American Geographers, 93(1), 165-185. https://doi.org/10.1111/1467-8306.93111

Bluestein, N., \& Acredelo, L. (1979). Developmental changes in map-reading skills. Child Development, 50, 691-697. https://doi.org/10.2307/1128934

Borriello, G. A., \& Liben, L. S. (2018). Encouraging maternal guidance of preschoolers' spatial thinking during block play. Child Development, 89(4), 1209-1222. https://doi.org/10.1111/cdev.12779

Bremner, J. G., \& Andreasen, G. (1998). Young children's ability to use maps and models to find ways in novel spaces. British Journal of Developmental Psychology, 16(2), 197-218. https://doi.org/10.1111/j.2044-835X.1998.tb00919.x

C. Titze, C., Jansen, P., \& Heil, M. (2010). Mental rotation performance and the effect of gender in fourth graders and adults. The European Journal of Developmental Psychology, 7(4), 432-444. https://doi.org/10.1080/17405620802548214

Casey, B. M., Andrews, N., Schindler, H., Kersh, J. E., Samper, A., \& Copley, J. (2008). The development of spatial skills through interventions involving block building activities. Cognition and Instruction, 26(3), 269-309. https://doi.org/10.1080/07370000802177177

Ferrara, K., Hirsh-Pasek, K., Newcombe, N. S., Golinkoff, R. M., \& Lam, W. S. (2011). Block talk: Spatial language during block play. Mind Brain Education, 5(3), 143-151. https://doi.org/10.1111/j.1751-228X.2011.01122.x

Gersmehl, P. J., \& Gersmehl, C. A. (2007). Spatial thinking by young children: Neurologic evidence for early development and educability. The Journal of Geography, 106(5), 181-191.

https://doi.org/10.1080/00221340701809108

Ginsburg, H. P., \& Amit, M. (2008). What is teaching mathematics to young children? A theoretical perspective and case study. Journal of Applied Developmental Psychology, 29(4), 274-285.

https://doi.org/10.1016/j.appdev.2008.04.008 
Gunderson, E. A., Ramirez, G., Beilock, S. L., \& Levine, S. C. (2012). The relation between spatial skill and early number knowledge: The role of the linear number line. Developmental Psychology, 48, 1229-1241. https://doi.org/10.1037/a0027433

Güven, Y. (2004). Erken çocuklukta matematiksel düşünme ve matematiği ögrrenme. İstanbul: Küçük Adımlar Eğitim Yayınları.

Horton, N. J., \& Lipsitz, S. R. (1999). Review of software to fit Generalized Estimating Equation Regression Models. The American Statistician, 53, 160-169.

Hoyek, N., Collet, C., Fargier, P., \& Guillot, A. (2012). The use of the Vandenberg and Kuse mental rotation test in children. Journal of Individual Differences, 33, 62-67. https://doi.org/10.1027/1614-0001/a000063

Huttenlocher, J., Newcombe, N. S., \& Vasilyeva, M. (1999). Spatial scaling in young children. Psychological Science, 10, 393-398. https://doi.org/10.1111/1467-9280.00175

Ilen, L. (2016). Mental rotation and mental folding in 7 and 8 years old children. Master's thesis, University of Jyvaskyla.

Kim, M., Bednarz, R., \& Kim, J. (2012). The ability of young Korean children to use spatial representations. International Research in Geographical and Environmental Education, 21(3), 261-277. https://doi.org/10.1080/10382046.2012.698089

Kızılçaoğlu, A. (2007). Harita Becerilerine Pedagojik Bir Bakış. Selçuk Üniversitesi Sosyal Bilimler Enstitüsü Dergisi, $18,341-358$.

Levine, S. C., Huttenlocher, J., Taylor, A., \& Langrock, A. (1999). Early sex differences in spatial skill. Developmental Psychology, 13, 320-325. https://doi.org/10.1037/0012-1649.35.4.940

Levine, S. C., Ratliff, K. R., Huttenlocher, J., \& Cannon, J. (2012). Early puzzle play: a predictor of preschoolers' spatial transformation skill. Developmental Psychology, 48(2), 530. https://doi.org/10.1037/a0025913

Levine, S. C., Vasilyeva, M., Lourenco, S. F., Newcombe, N. S., \& Huttenlocher, J. S. (2005) Socioeconomic status modifies the sex difference in spatial skill. Psychological Science, 16, 841-845. https://doi.org/10.1111/j.1467-9280.2005.01623.x

Liang, K. Y., \& Zeger, S. L. (1986). Longitudinal data analysis using Generalized Linear Models. Biometrika, 73, 13-22. https://doi.org/10.1093/biomet/73.1.13

Liben, L. S., \& Downs, R. M. (1993). Understanding person-space-map relations: Cartographic and developmental perspectives. Developmental Psychology, 29, 739-752. https://doi.org/10.1037/0012-1649.29.4.739

Loewenstein, J., \& Gentner, D. (2001). Spatial mapping in preschoolers: Close comparisons facilitate far mappings. Journal of Cognition and Development, 2(2), 189-219. https://doi.org/10.1207/S15327647JCD0202_4

Melendez, W., Beck, V., \& Fletcher, M. (2000). Teaching Social Studies in Early Education. United States: Delmar Thompson Learning.

Michaelidou, E., Filippakopoulou, V., \& Nakos, B. (2007). Children's choice of visual variables for thematic maps. Journal of Geography, 106, 49-60. https://doi.org/10.1080/00221340601188686

Newcombe, N. S., \& Frick, A. (2010). Early education for spatial intelligence: Why, what and how. Mind, Brain and Education, 4, 102-111. https://doi.org/10.1111/j.1751-228X.2010.01089.x

Newcombe, N. S., \& Huttenlocher, J. (2000). Making space: The development of spatial representation and reasoning. MIT Press. https://doi.org/10.7551/mitpress/4395.001.0001

Newcombe, N. S., \& Learmonth, A. E. (2005). The development of spatial competence. In P. Shah \& A. Miyake (Eds.), Handbook of Visuospatial Thinking. Cambridge University Press. 213-256. https://doi.org/10.1017/CBO9780511610448.007

Peter, M., Glück, J., \& Beiglböck, W. (2010). Map understanding as a developmental marker in childhood. Journal of Individual Differences, 31(2), 64-67. https://doi.org/10.1027/1614-0001/a000011

Ping, R., Ratliff, K., E. Hickey, E., \& Levine, S. C. (2011). Using manual rotation and gesture to improve mental rotation in preschoolers. Proceedings of the XXXIV Annual Meeting of the Cognitive Science Society, 459-464

Plester, B., Blades, M., \& Spencer, C. (2006). Children understanding of environmental representation: Aerial photographs and model town. In. Spencer, C. \& Blades, M. (Eds.). Children and their environment: Learning, using and designing spaces. 42-72. Newyork: Cambridge University Press. 
Sandberg, E. H., \& Huttenlocher, J. (2001). Advanced spatial skills and advance planning: components of 6-year-olds' navigational map use. Journal of Cognition and Development, 2, 51-70. https://doi.org/10.1207/S15327647JCD0201_3

Sarı, M. H. (2016). Uzamsal Beceri ve Uzamsal Kaygı Arasındaki İlişki: Sınıf Öğretmeni Adayları Üzerine Bir Araştırma. Turkish Journal of Computer and Mathematics Education, 7(3), 646-658. https://doi.org/10.16949/turkbilmat.277877

Shusterman, A., Lee, S. A., \& Spelke, E. (2008). Young children's spontaneous use of geometric information in maps. Developmental Science, 11(2), F1-F7. https://doi.org/10.1111/j.1467-7687.2007.00670.x

Spelke, E. S., Gilmore, C. K., \& McCarthy, S. (2011). Kindergarten children's sensitivity to geometry in maps. Developmental Science, 14(4), 809-821. https://doi.org/10.1111/j.1467-7687.2010.01029.x

Stea, D., Kerkman, D., Pinon, M., Middlebrook, N., \& Rice, J. (2004). 'Pre-schoolers use maps to find hidden objects outdoors', Journal of Environmental Psychology, 24(3), 341-45. https://doi.org/10.1016/j.jenvp.2004.05.003

Tsubota, Y., \& Chen, Z. (2012). How do young children's spatio-symbolic skills change over short time scales. Journal of Experimental Psychology, 111, 1-21.

Turgut, M, Günhan, B. C., \& Yılmaz, S. (2009). Uzamsal yetenek hakkında bir bilgi seviyesi incelemesi. E-Journal of New World Sciences Academy Education Sciences, 4(2), 317-326.

Turgut, M., \& Yılmaz, S. (2012). Relationships among preservice primary mathematics teachers' gender, academic success and spatial ability. International Journal of Instruction, 5(2), 5-20.

Tzuriel, D., \& Egozi, G. (2010). Gender Differences in Spatial Ability of Young Children: The Effects of Training and Processing Strategies. Child Development, 81(5), 1417-1430. https://doi.org/10.1111/j.1467-8624.2010.01482.x

Vasilyeva, M., \& Bowers, E. (2010). Exploring the effects of similarity on mapping spatial relations. Journal of Experimental Child Psychology, 106, 221-239. https://doi.org/10.1016/j.jecp.2010.04.003

Verdine, B. N., Golinkoff, R. M., Hirsh-Pasek, K., Newcombe, N. S., Flipovicz, A. T., \& Chang, A. (2014). Deconstructing building blocks: preschoolers' spatial assembly performance relates to early mathematical skills. Child Development, 85(3), 1062-1076. https://doi.org/10.1111/cdev.12165

Vosmik, J. R. (2005). Facilitating Preschoolers' Spatial Mapping: Close Comparisons and Natural Misalignment. Arizona State University

Vosmik, J. R., \& Presson, C. C. (2004). Children's response to natural map misalignment during wayfinding. Journal of Cognition and Development, 5(3), 317-336. https://doi.org/10.1207/s15327647jcd0503_2

\section{Copyrights}

Copyright for this article is retained by the author(s), with first publication rights granted to the journal.

This is an open-access article distributed under the terms and conditions of the Creative Commons Attribution license which permits unrestricted use, distribution, and reproduction in any medium, provided the original work is properly cited. 